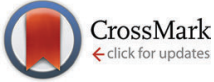

Cite this: Phys. Chem. Chem. Phys., 2015, 17, 16767

Received 20th March 2015, Accepted 19th May 2015

DOI: $10.1039 / c 5 c p 01628 b$

www.rsc.org/pccp

\title{
Unusual hydroxyl migration in the fragmentation of $\beta$-alanine dication in the gas phase $\dagger$
}

\author{
Dariusz Grzegorz Piekarski, ${ }^{\text {a }}$ Rudy Delaunay, ${ }^{\text {bc }}$ Sylvain Maclot, ${ }^{\text {bc }}$ Lamri Adoui, $^{\text {bc }}$ \\ Fernando Martín, ${ }^{\text {ad }}$ Manuel Alcamí, ${ }^{\text {ad }}$ Bernd A. Huber, ${ }^{\mathrm{b}}$ Patrick Rousseau, \\ Alicja Domaracka ${ }^{b}$ and Sergio Díaz-Tendero*a
}

\begin{abstract}
We present a combined experimental and theoretical study of the fragmentation of doubly positively charged $\beta$-alanine molecules in the gas phase. The dissociation of the produced dicationic molecules, induced by low-energy ion collisions, is analysed by coincidence mass spectrometric techniques; the coupling with $a b$ initio molecular dynamics simulations allows rationalisation of the experimental observations. The present strategy gives deeper insights into the chemical mechanisms of multiply charged amino acids in the gas phase. In the case of the $\beta$-alanine dication, in addition to the expected Coulomb explosion and hydrogen migration processes, we have found evidence of hydroxyl-group migration, which leads to unusual fragmentation products, such as hydroxymethyl cation, and is necessary to explain some of the observed dominant channels.
\end{abstract}

\section{Introduction}

Dicationic species, extensively studied due to their unusual stability and reactivity, ${ }^{1,2}$ are involved in the creation of new biomolecules in planets atmospheres ${ }^{3}$ and in the interstellar media. ${ }^{4}$ Numerous amino acids were detected in Carbonaceous Ivuna chondrites, a type of meteorite, with the simplest $\beta$-amino acid, $\beta$-alanine $\left(\mathrm{NH}_{2} \mathrm{CH}_{2} \mathrm{CH}_{2} \mathrm{COOH}\right)$ as the most abundant one. ${ }^{5}$ This finding can be considered as the manifestation of spontaneous gas phase synthesis of amino acids in the interstellar space.

Moreover, previous theoretical and experimental works showed the important role played by organic radical cations in various chemical reactions, ${ }^{6-9}$ where the first step is the ionisation of the molecule. For instance an important electrophilic modification of amino acids which takes place after ionisation or nitrosation of alanine $e^{10-12}$ produces lactic acid. ${ }^{13}$ Therefore, there is a need to understand the chemical behavior of charged amino acids.

\footnotetext{
${ }^{a}$ Departamento de Química, Módulo 13, Universidad Autónoma de Madrid, 28049 Madrid, Spain. E-mail: dariusz.piekarski@uam.es, sergio.diaztendero@uam.es

${ }^{b}$ CIMAP (UMR 6252) - CEA, CNRS, ENSICAEN, Unicaen, Blvd. Henri Becquerel, BP 5133, 14070 Caen Cedex 5, France

${ }^{c}$ Université de Caen Basse-Normandie, Esplanade de la Paix, CS 14032, 14032 Caen Cedex 5, France

${ }^{d}$ Instituto Madrileño de Estudios Avanzados en Nanociencias (IMDEA-Nanociencia), Cantoblanco 28049, Madrid, Spain

$\dagger$ Electronic supplementary information (ESI) available: Details of the experimental procedure and of the theoretical simulations together with some complementary results. See DOI: $10.1039 / \mathrm{c} 5 \mathrm{cp} 01628 \mathrm{~b}$
}

In particular, the fragmentation of positively charged $\beta$-alanine has been the object of extensive investigations. ${ }^{14-17}$ In single ionisation of $\beta$-alanine, and other small amino acids, it was found that the loss of the carboxylic group is one of the dominant processes. ${ }^{14-16}$ In the $\alpha$-alanine case, photoionisation experiments showed that the principal cationic fragment produced corresponds to $\mathrm{NH}_{2} \mathrm{CH}_{3} \mathrm{CH}^{+}$, formed by the loss of the $\mathrm{COOH}$ radical in a simple $\mathrm{C}_{\text {carboxylic }}-\mathrm{C}_{\alpha}$ bond cleavage. ${ }^{18} \mathrm{C}_{\alpha}-\mathrm{C}_{\beta}$ and $\mathrm{C}_{\beta}-\mathrm{C}_{\gamma}$ bond breaking are the dominant channels for $\beta$-amino acids ${ }^{19}$ and $\gamma$-amino acids, ${ }^{20}$ respectively. For more complex amino acids side chain bond breaking appears in competition. ${ }^{15,16}$ For double ionisation, simple Coulomb explosion is expected to dominate along the same bond cleavage mentioned above. ${ }^{20,21}$

In this work, we join theoretical and experimental efforts. $A b$ initio molecular dynamics and exploration of the potential energy surface (PES) together with multiple-coincidence mass spectrometry techniques allow us to identify all possible exit channels and fragmentation mechanisms following the ionisation processes for excited doubly charged $\beta$-alanine in the gas phase. We have found unusual fragmentation mechanism implying hydroxyl group $(\mathrm{OH})$ migration. They appear in competition with other processes such as hydrogen transfer ${ }^{21}$ or Coulomb explosion. These findings are of high relevance for a better understanding of radiation damage processes, since hydroxyl radicals have been identified as one of the main factors responsible for such damage. ${ }^{22-25}$ Indeed, it has been shown that in biological tissues the damages produced in the biomolecules are not only caused directly by the particle-matter collision but also by radicals and secondary particles created after the fragmentation of different chemical species along the ionisation path. ${ }^{26,27}$ 
Radiation damage of biological tissues at the molecular level has been widely studied by employing experimental techniques involving interaction of biomolecules with ionising particles (X-rays, electrons, ions) in the gas phase ${ }^{28-31}$ in combination with theoretical simulations..$^{20,21,30,32,33}$

Moreover, the migration of the hydroxyl group has been shown to be a crucial step in the mechanistic processes of enzymes, such as the propanediol dehydratase, ${ }^{34,35}$ and has been widely evaluated by theoretical simulations. ${ }^{36-38}$ The proposed processes in these former studies differ from the mechanisms presented in this work, mainly because in doubly-charged $\beta$-alanine, the charge drives the first steps in the fragmentation and thus, the $\mathrm{OH}$ migration can be considered as a consequence of the bond breaking due to Coulomb explosion. The importance of $\mathrm{OH}$ migration is highlighted here because it leads to ionic products detected with high intensity in the experiments $\left(\mathrm{NH}_{2} \mathrm{CH}_{2}{ }^{+}\right.$in coincidence with $\left.\mathrm{CH}_{2} \mathrm{OH}^{+}\right)$, i.e. they come from a dominant channel.

\section{Methods}

\section{Computational details}

Quantum chemistry calculations were carried out using the density functional theory (DFT). In particular, geometry optimisations were performed using the B3LYP functional, which combines the Becke's three parameter non-local hybrid exchange potential ${ }^{39}$ with the non-local correlation functional of Lee, Yang and Parr. ${ }^{40}$ This functional has been used in combination with the 6-311++G(d,p) basis set. This method has shown to provide an accurate description of the PES of cationic amino acids. $^{7,15,20,21,41}$ Harmonic vibrational frequencies have been also evaluated at the same level to characterise minima and transition states in the PES and to compute the zero point energy (ZPE) correction. For the obtained transition states, intrinsic reaction coordinate (IRC) calculations have been carried out to verify the minima they connect. ${ }^{42}$

$A b$ initio molecular dynamics (AIMD) were performed using the atom-centered Density Matrix Propagation method (ADMP), ${ }^{43-46}$ employing the B3LYP functional together with the $6-31++G(d, p)$ basis set. The simulations were carried out using a time step of $\Delta t=0.1 \mathrm{fs}$, a fictitious mass of $\mu=0.1 \mathrm{amu}$ and a maximum simulation time of $t_{\max }=300 \mathrm{fs}$. To mimic the experimental conditions we have performed the AIMD simulations in the gas phase by introducing a certain amount of excitation energy, $E_{\text {exc }} \approx 0.03-4.08 \mathrm{eV}$, and extracting the two electrons from the highest occupied molecular orbital (HOMO) in a FranckCondon type transition. This energy range covers the estimated excitation energy in collisions of highly-charged ions with amino acids in the gas phase..$^{20,21,47}$ In the collisions of other type of biomolecules, such as adenine with singly charged ions, a higher excitation energy has been measured $(\sim 8 \mathrm{eV})$ due to the different conditions. ${ }^{48}$ The internal energy was randomly distributed over all the vibrational degrees of freedom in each trajectory. In this way, we reproduce the sudden ionisation and excitation process produced in gas phase collisions of ions with neutral $\beta$-alanine molecules. The AIMD simulations were carried out considering the 12 most stable conformers of neutral $\beta$-alanine in the gas phase. ${ }^{49}$ For each isomer and each value of the excitation energy we run 20 trajectories. Statistics were then performed over these trajectories. All the calculations were performed using the Gaussian09 program. ${ }^{50}$

\section{Experimental details}

Products of the interaction between $\mathrm{O}^{6+}$ ions and isolated $\beta$-alanine molecules in the gas phase were studied by means of coincidence time-of-flight (TOF) mass spectrometry. The experiments were performed at the low-energy ion beam facility ARIBE of GANIL in Caen, France. The experimental setup has been described in detail elsewhere, ${ }^{51}$ only a brief description is given here. The $\mathrm{O}^{6+}$ ions beam was extracted from the electron cyclotron resonance ion source, mass selected, pulsed, collimated and transported in the interaction zone where the beam crossed a molecular effusive jet of neutral $\beta$-alanine molecules produced by the evaporation of a powder from a heated oven device at $400 \mathrm{~K}$. Cationic products of the interaction were extracted into WileyMcLaren linear time-of-flight mass spectrometer. ${ }^{52}$ At the end of the free-flight region of the spectrometer (TOF tube of $1 \mathrm{~m}$ length) these products were accelerated and impacted a gold-coated plate producing secondary electrons which are detected by a microchannel plate detector after deflection by a weak magnetic field produced by Helmholtz coils. This Daly-type detector allowed efficient and uniform detection of the interaction products. The arrival times were measured in an event-by-event mode over a wide mass-over charge $(\mathrm{m} / \mathrm{z})$ ratio range. Each event was characterised by the number of detected fragments and their associated time-of-flight. This allowed to construct the correlation between the charged fragments proceeding from a single ionmolecule interaction (for details see ref. 20).

\section{Results and discussion}

The total mass spectrum of positively charged products from collisions of $\mathrm{O}^{6+}$ at $48 \mathrm{keV}$ ions with neutral $\beta$-alanine molecules in the gas phase is shown in Fig. 1. A strong peak associated with the intact molecule $(\mathrm{m} / \mathrm{z}=89 \mathrm{amu})$ is observed and represents $3 \%$ of the total intensity. However, the mass spectrum is dominated by fragmentation products. The dominant exit channels for heavier fragments $(\mathrm{m} / \mathrm{z} \geq 24 \mathrm{amu})$ come from $\mathrm{C}_{\text {carboxylic }}-\mathrm{C}_{\alpha}$ and $\mathrm{C}_{\alpha}-\mathrm{C}_{\beta}$ bond cleavages and subsequent fragmentations. The peak at $\mathrm{m} / \mathrm{z}=30 \mathrm{amu}$ dominates the spectrum and corresponds to the iminium cation $\left(\mathrm{NH}_{2} \mathrm{CH}_{2}^{+}\right)$. Fragment ion assignments to the most intense peaks have already been made in previous works. ${ }^{14,18}$ Interestingly, in the inclusive mass spectrum we can also observe the presence of molecular dications like in the case of the simplest amino acid glycine. ${ }^{21}$ The different chemical mechanisms leading to cationic fragments are inferred with the quantum chemistry simulations. We first present the theoretical results obtained in the $a b$ initio molecular dynamics simulations. In the 4080 trajectories performed for the doubly charged $\beta$-alanine, we have characterised seventeen different 

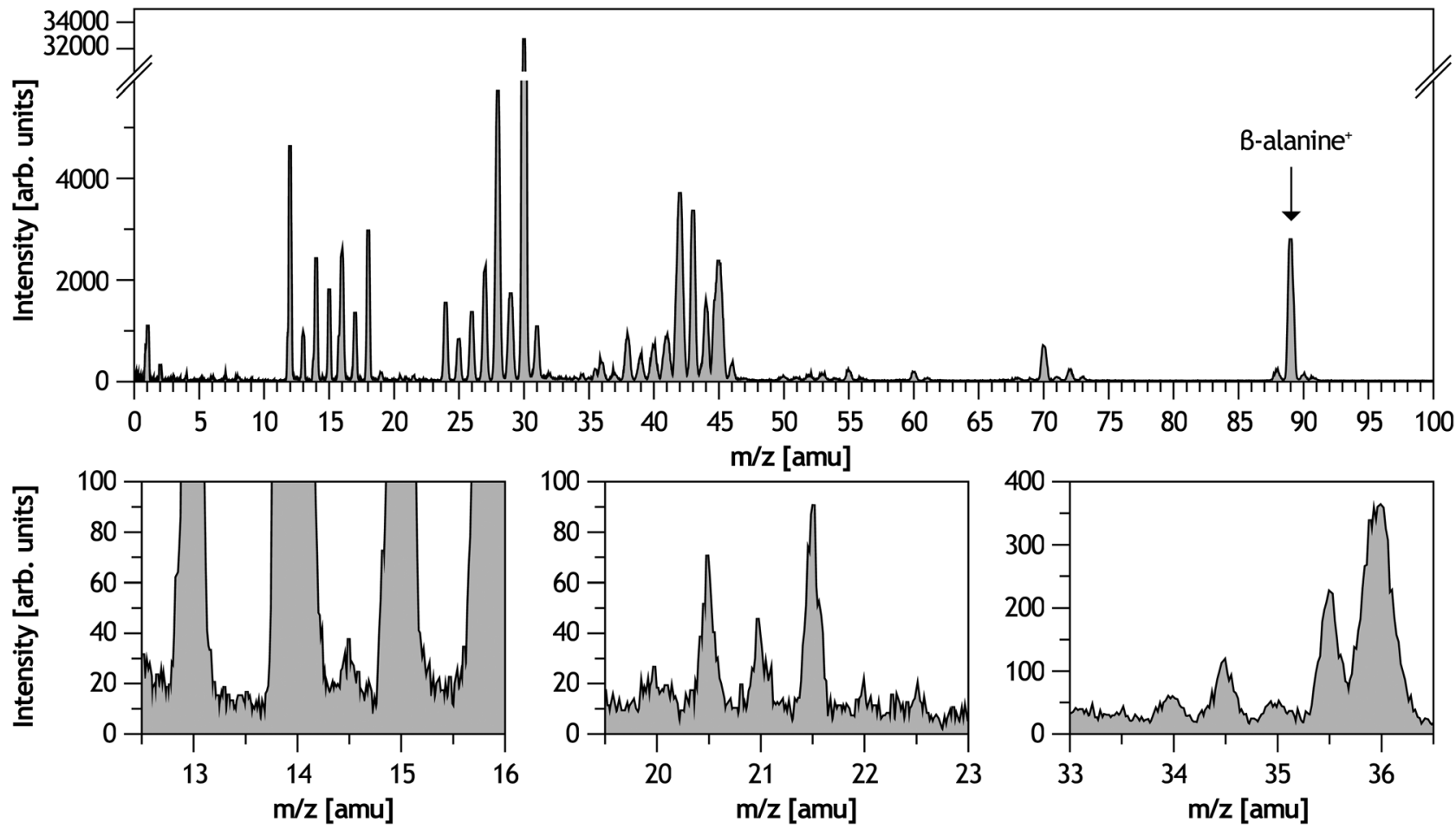

Fig. 1 Mass spectrum of cationic products from collisions between $\mathrm{O}^{6+}$ ions at $48 \mathrm{keV}$ and neutral $\beta$-alanine molecules in the gas phase. 3 zoom-ins enlight the presence of doubly positively charged products in the mass range of 13-16, 20-23 and 33-36 amu.

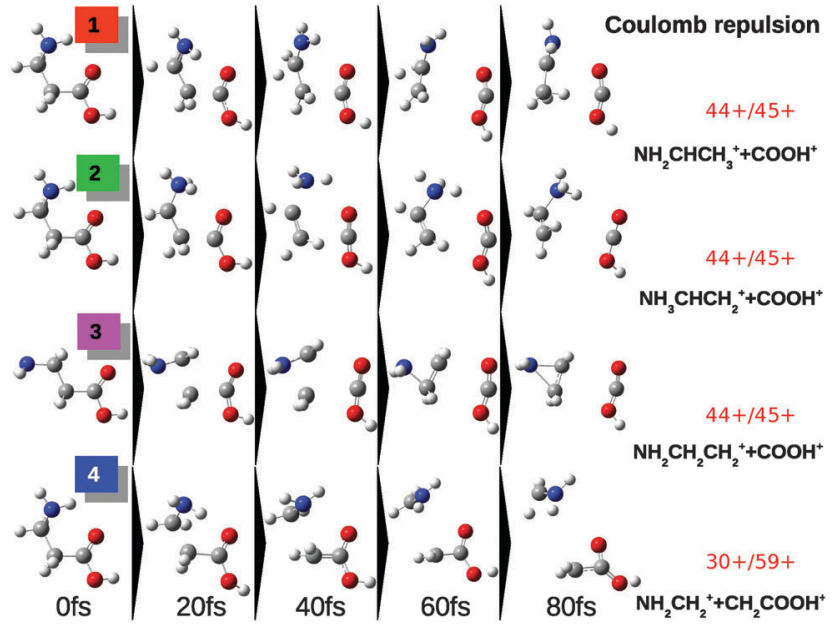

Fig. 2 Snapshots of molecular dynamics simulations of a $\beta$-alanine dication showing Coulomb explosion, i.e. charge separation processes: (a) $\mathrm{C}_{\text {carboxylic }}{ }^{-}$ $\mathrm{C}_{\alpha}$ bond breaking: (1) $\mathrm{NH}_{2} \mathrm{CHCH}_{3}{ }^{+} / \mathrm{COOH}^{+}$, (2) $\mathrm{NH}_{3} \mathrm{CHCH}_{2}{ }^{+} / \mathrm{COOH}^{+}$, (3) $\mathrm{NH}_{2} \mathrm{CH}_{2} \mathrm{CH}_{2}{ }^{+} / \mathrm{COOH}^{+}$; (b) $\mathrm{C}_{\alpha}-\mathrm{C}_{\beta}$ bond breaking: (4) $\mathrm{NH}_{2} \mathrm{CH}_{2}{ }^{+} / \mathrm{CH}_{2} \mathrm{COOH}^{+}$

mechanisms that can be classified into three groups: (i) Coulomb explosion, (ii) isomerisation and (iii) combined processes. Ten snapshots of these processes are shown in Fig. 2,3 and 4 , respectively. Trajectories 1, 2, 3, 4, 5, 9 and 10 are observed with larger probability and represent the main fragmentation mechanisms. Detailed information of all mechanisms is given in the ESI. $\dagger$

The Coulomb explosion dominates (see Fig. 5a). Four different Coulomb explosion processes can be distinguished (see Fig. 2): $\mathrm{C}_{\text {carboxylic }}{ }^{-} \mathrm{C}_{\alpha}$ bond cleavage leading to (1) $\mathrm{NH}_{2} \mathrm{CHCH}_{3}{ }^{+}+$ $\mathrm{COOH}^{+}$, (2) $\mathrm{NH}_{3} \mathrm{CHCH}_{2}^{+}+\mathrm{COOH}^{+}$and (3) $\mathrm{NH}_{2} \mathrm{CH}_{2} \mathrm{CH}_{2}{ }^{+}+\mathrm{COOH}^{+}$; and $\mathrm{C}_{\alpha}-\mathrm{C}_{\beta}$ bond cleavage leading to (4) $\mathrm{NH}_{2} \mathrm{CH}_{2}{ }^{+}+\mathrm{CH}_{2} \mathrm{COOH}^{+}$. Among them, channels (1) and (4) strongly dominate with $\approx 40 \%$ and $30 \%$, respectively (see Fig. $5 \mathrm{~b}$ ). In the processes (1) and (2) we observe $\mathrm{H}$ migration to the terminal $\mathrm{C}$ and $\mathrm{N}$ atoms, stabilising the produced iminium and ammonium cation, respectively. On the other hand, the mechanism (3) is an example of geometry reorganisation, leading to a stable cyclic isomer of the $\mathrm{NH}_{2} \mathrm{CH}_{2} \mathrm{CH}_{2}{ }^{+}$ cation. The carboxyl ion $\left(\mathrm{COOH}^{+}\right)$produced in (1), (2) and (3) is very stable. However, fragmentation of this ion was evaluated for other organic systems leading to strongly observed signals at $28^{+}$and $29^{+}$, associated with $\mathrm{CO}^{+}$and $\mathrm{COH}^{+}$, respectively. ${ }^{53}$ Mechanism (4) leads to the very stable $\mathrm{NH}_{2} \mathrm{CH}_{2}{ }^{+}$cation, which dominates the mass spectrum.

Fig. 3 shows the time evolution of different isomerisation processes of $\beta$-alanine leading to the $\mathrm{diol}^{2+}(5), 5$-membered ring $^{2+}(6)$, linear $\mathrm{NH}_{3} \mathrm{CH}_{2} \mathrm{CHCOOH}^{2+}(7)$ and 4-membered ring ${ }^{2+}$ (8) structures. Only one of them does not show $\mathrm{H}$ transfer and leads to the stable cyclic form of $\beta$-alanine ${ }^{2+}$ (mechanism (6) in Fig. 3). This structure has not been previously reported, but a similar 5-membered ring intermediate (ozalone) was proposed by Harrison, ${ }^{54}$ after fragmentation of a peptide followed by further elimination of water. 5-Membered ring structures were previously observed after hydrogen migration and water emission in the homologous series of carboxylic acids $\mathrm{HOOC}\left(\mathrm{CH}_{2}\right)_{n} \mathrm{COOH}^{53}$ In competition with cyclisation the formation of linear $\mathrm{NH}_{3} \mathrm{CH}_{2} \mathrm{CHCOOH}^{2+}$ is also observed, which requires $\mathrm{H}$ transfer and appears sporadically in the simulations. $\mathrm{H}$ transfer in amino 


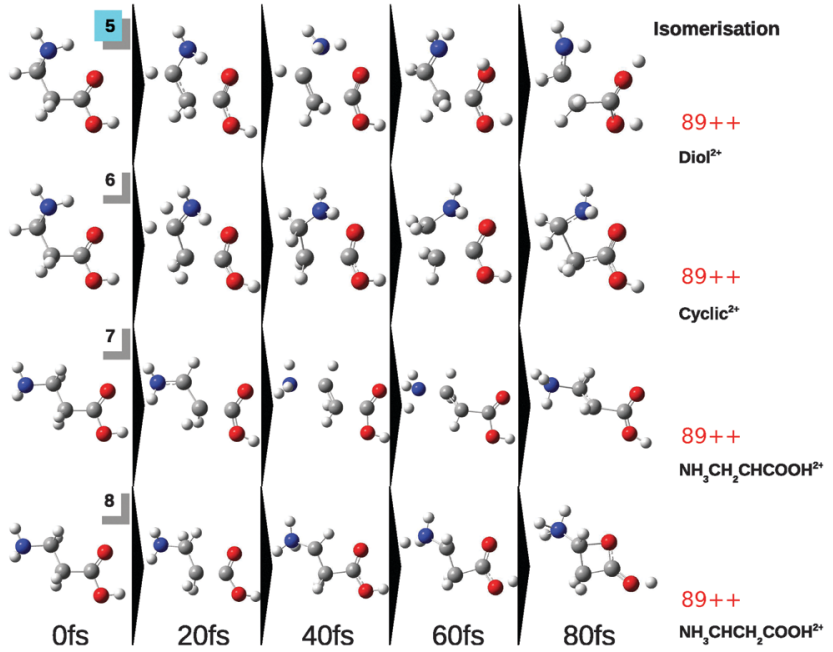

Fig. 3 Snapshots of molecular dynamics simulations of a $\beta$-alanine dication showing isomerisation processes: (5) diol $^{2+}$, (6) 5-membered ring dication, (7) linear $\mathrm{NH}_{3} \mathrm{CH}_{3} \mathrm{CHCOOH}^{2+}$ and (8) 4-membered ring dication. acids is commonly observed in solution ${ }^{12,55}$ and has been recently reported in the gas phase after the interaction with highly charged ions. ${ }^{21}$

Combined processes are defined as those trajectories that show Coulomb explosion and molecular rearrangement simultaneously. They are also associated with the emission of neutral moieties. The most important and dominant complex molecular rearrangement of those observed (see Fig. 4) is the migration of the hydroxyl group, leading to the emission of neutral carbon monoxide: $\mathrm{NH}_{2} \mathrm{CH}_{2}{ }^{+}+\mathrm{CH}_{2} \mathrm{OH}^{+}+\mathrm{CO}$ (mechanism (9)). This mechanism appears in competition with Coulomb explosion showing $\approx 15 \%$ of probability. Another observed channel is $\mathrm{NH}_{2} \mathrm{CCH}_{2}{ }^{+}+\mathrm{H}_{2}+\mathrm{COOH}^{+}$(10). Mechanisms leading to emission of neutral $\mathrm{CO}_{2}, \mathrm{NH}_{3}$ and $\mathrm{CH}_{2}$ also appear (see $\mathrm{ESI} \dagger$ ) but they are very rare processes (with less than $2 \%$ of probability).

It is important to notice that the fragmentation pattern strongly depends on the geometry of the conformers (see details in the ESI $\dagger$ ). This can be explained by the fact that the structure of the dication formed at the initial stage of the fragmentation (in the ionisation) determines the reaction path and, thus,

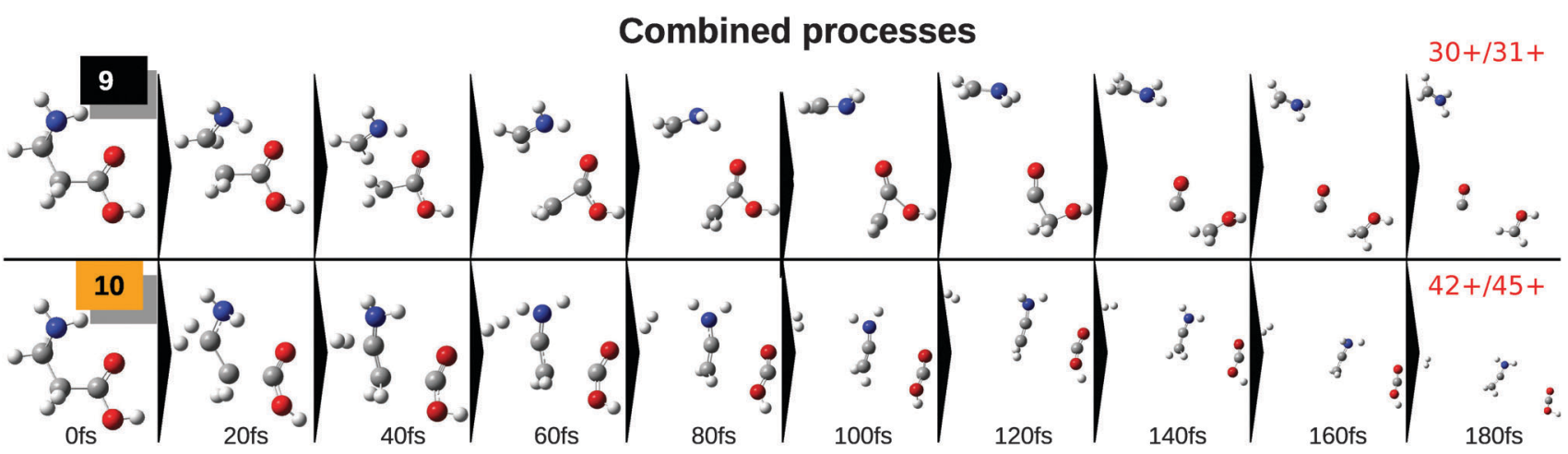

Fig. 4 Snapshots of molecular dynamics simulations of a $\beta$-alanine dication showing combined processes: (9) OH migration, (10) Coulomb explosion and hydrogen molecule emission; all combined mechanisms available in ESI. $\dagger$

(a)

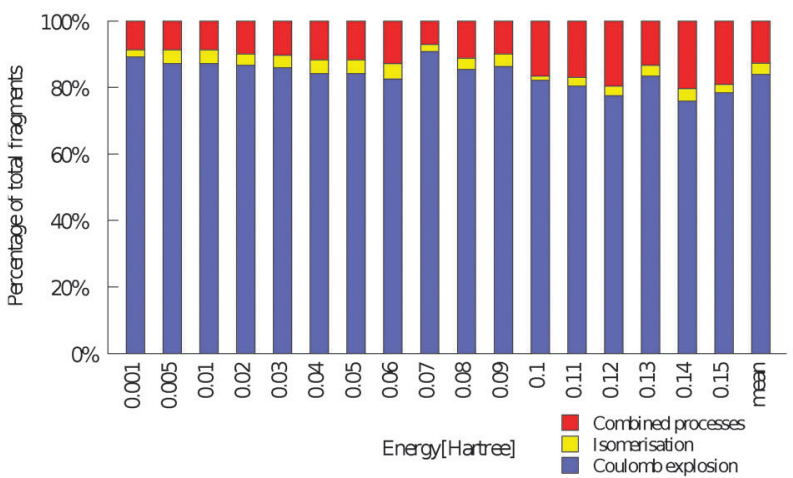

(b)

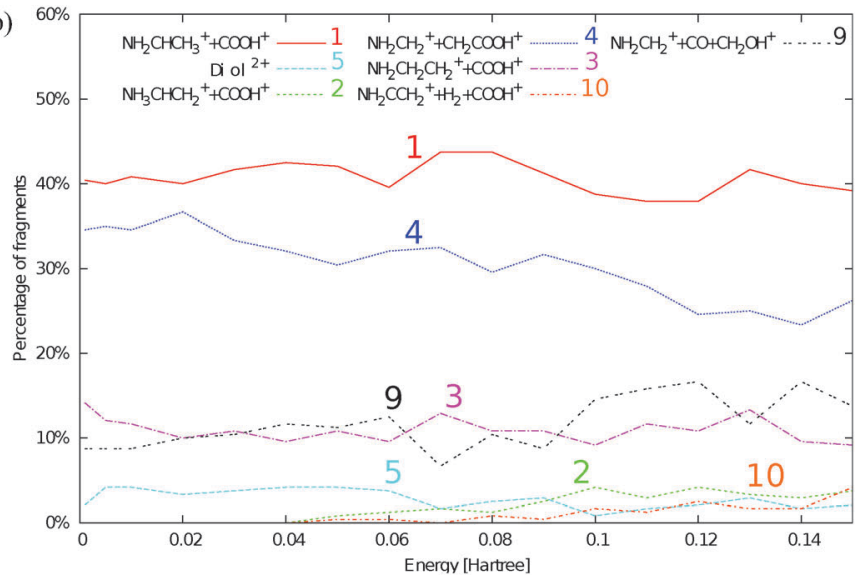

Fig. 5 Ab initio molecular dynamics statistics for all neutral conformers of $\beta$-alanine and percentage of the most important fragmentation channels. Both quantities are given as a function of the internal excitation energy (in Hartrees). A detailed analysis for the statistics of each neutral conformer is included in the ESI. $\dagger$ (a) Competition between Coulomb explosion vs. isomerisation vs. combined processes for all studied conformers of $\beta$-alanine with relative energy $\approx 2 \mathrm{kcal} \mathrm{mol}^{-1}$. (b) Percentage of the most important fragmentation channels as a function of the excitation energy (in Hartree) for all studied conformers of $\beta$-alanine with relative energy $\approx 2 \mathrm{kcal} \mathrm{mol}^{-1}$. 
the fragmentation products. ${ }^{56}$ However, since the temperature in the oven is $400 \mathrm{~K}$, only the most stable neutral conformers will be populated before the collision and thus, not all the conformers included in the calculations will contribute to the fragmentation pattern because they are too high in energy to be present in the beam. Statistical details about all mechanisms are presented in the ESI. $\dagger$

Molecular dynamics simulations were performed up to 300 fs. To evaluate the energetics and the mechanisms of the subsequent processes we have thoroughly explored the potential energy surface (PES). The exploration of the PES has been performed starting from the most probable and relevant processes as observed in the statistics of the molecular dynamics simulations: i.e. mechanisms (1), (2), (3), (4), (5), (9) and (10). Firstly, we calculated all of the possible pathways corresponding to the mechanisms obtained in the molecular dynamics simulations. Later, we associated the lowest energy channels with the peaks observed in the experimental measurements. Using this approach we obtained a complete picture of the fragmentation dynamics and further energetic information of each channel which becomes comparable with the experimental measurements, done at the $\mu$ s timescale. We present these results separately considering the following order: (a) $\mathrm{C}_{\text {carboxyl }}{ }^{-}$ $\mathrm{C}_{\alpha}$ bond cleavage, (b) $\mathrm{C}_{\alpha}-\mathrm{C}_{\beta}$ bond cleavage, (c) $\mathrm{H}$ migration and (d) unexpected $\mathrm{OH}$ migration.

\section{(a) $\mathrm{C}_{\text {carboxyl }}{ }^{-} \mathrm{C}_{\alpha}$ bond breaking}

Fig. 6 shows zooms in the most interesting regions of the correlation map, which displays the time-of-flights (in ns) of the heavier fragments (TOF 2) as a function of the time-offlights of the lighter ones (TOF 1). It shows the islands with the highest intensities with special emphasis on the ion pairs $\left(42^{+} / 45^{+}\right),\left(30^{+} / 42^{+}\right),\left(30^{+} / 31^{+}\right)$and $\left(28^{+} / 30^{+}\right)$. Direct bond cleavage of $\beta$-alanine does not explain most of these islands. The assignments of such species and the understanding of their production require some complementary studies. Quantum chemistry calculations allow us to propose the mechanisms underlying the formation of the different molecular cations observed after $\mathrm{C}_{\text {carboxyl }}{ }^{-} \mathrm{C}_{\alpha}$. Starting from the $\mathrm{NH}_{2} \mathrm{CHCH}_{3}{ }^{+}+\mathrm{COOH}^{+}$exit channel we can easily explain the peaks observed in the zoom on the coincidence map (Fig. 6a). Fig. 7 presents the part of potential energy surface corresponding to these pathways. The most intense islands related to $\mathrm{C}_{\text {carboxyl }} \mathrm{C}_{\alpha}$ are those corresponding to $\mathrm{COOH}^{+}(m / z=45 \mathrm{amu})$ in correlation with other species: $\mathrm{m} / \mathrm{z}=44,43,42$ and $41 \mathrm{amu}$. Processes corresponding to further fragmentation of the $\mathrm{COOH}^{+}$appear at much higher energy and thus, the corresponding islands contribute in much lower percentage in the correlation map: slight signals coming from $\mathrm{COOH}^{+}$fragmentation due to $\mathrm{O}$ or $\mathrm{OH}$ emissions are observed, similarly to those previously reported in the literature. ${ }^{53}$ The coincidence measurement at $\left(44^{+} / 45^{+}\right)$presents low intensity. This is in agreement with the simulations assuming that $\mathrm{NH}_{2} \mathrm{CHCH}_{3}{ }^{+}(m / z=44 \mathrm{amu})$ possesses enough internal energy to undergo further fragmentation since this channel is almost $9 \mathrm{eV}$ below the entrance channel (1st +2 nd vertical ionisation potential, VIP). The observation of the islands at $\left(43^{+} / 45^{+}\right)$and $\left(42^{+} / 45^{+}\right)$
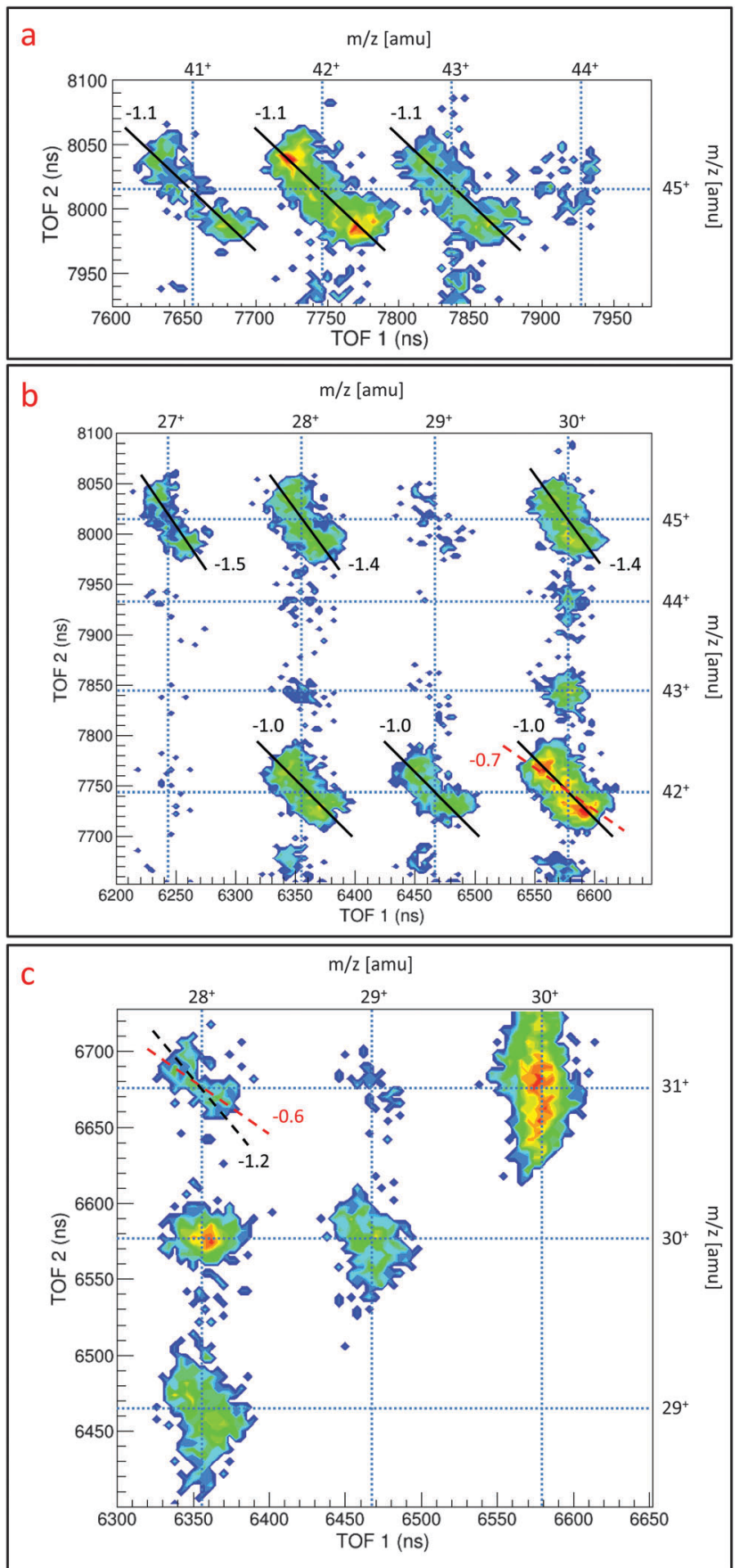

Fig. 6 Coincidence map for the fragmentation of the $\beta$-alanine dication into two charged fragments after the interaction of neutral $\beta$-alanine with $\mathrm{O}^{6+}$ ions at the energy of $48 \mathrm{keV}$. Regions of interest correspond to islands: (a) $45^{+}$with other heavy fragments $\left(43^{+}, 42^{+}, 41^{+}\right)$, (b) $42^{+}$and $45^{+}$with the $\mathrm{NH}_{x} \mathrm{CH}_{x}{ }^{+}$fragments $(1 \leq x \leq 2$ ), (c) lighter fragments coming from $\mathrm{OH}$ migration and associated with the fragment $31^{+}$. Experimental slopes values are associated with solid lines and dashed lines indicate different computed mechanisms.

corresponds to the emission of $\mathrm{H}$ and $\mathrm{H}_{2}$ from this fragment. The strong intensity of these islands in the correlation map (Fig. 6a) confirm the proposed mechanisms. The peak at $m / z=43 \mathrm{amu}$ is assigned to $\mathrm{NH}_{2} \mathrm{CCH}_{3}{ }^{+}$and $\mathrm{NH}_{2} \mathrm{CHCH}_{2}{ }^{+}$(see Fig. 7); they are cationic forms of acetaldimine and vinylamine, respectively. 


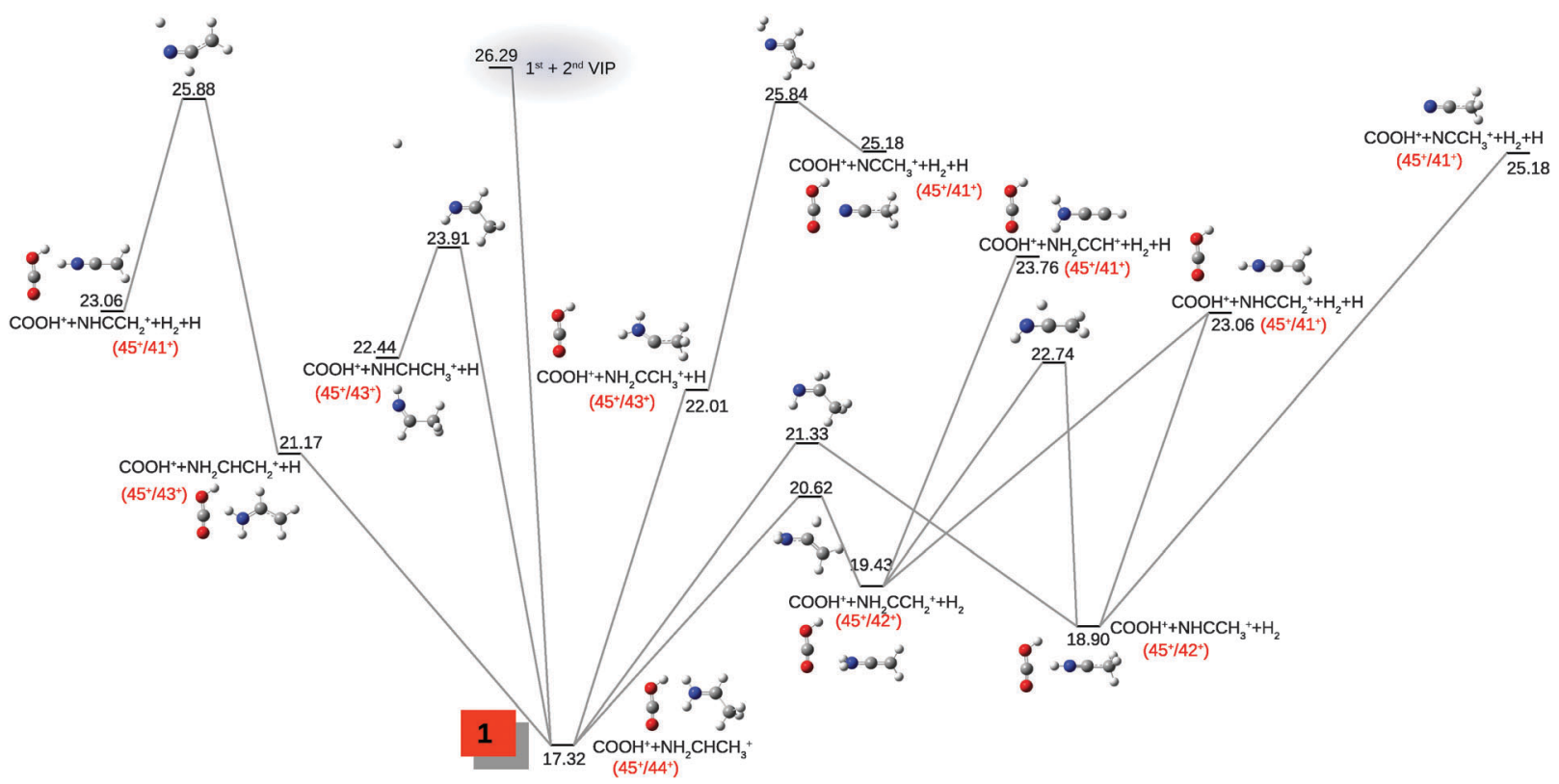

Fig. 7 Fragmentation pathways for doubly positively charged $\beta$-alanine - stationary points of the potential energy surface corresponding to $C_{\text {carboxyl }}-C_{\alpha}$ bond breaking and further fragmentation pathways leading to charged fragments: $\mathrm{m} / \mathrm{z}=45 \mathrm{amu}$ in coincidence with other charged fragments $(\mathrm{m} / \mathrm{z}=43$, $42,41 \mathrm{amu})$. Relative energies, $\Delta E$, are given in $\mathrm{eV}$ at the DFT-B3LYP/6-311++G(d,p) level of theory including the zero point energy correction with respect to the most stable isomer of the neutral molecule. Correlation notation is also included, e.g. the pair $\left(44^{+} / 45^{+}\right)$.

After emission of one hydrogen atom, dehydrogenated acetaldimine $\left(\mathrm{NHCCH}_{3}^{+}\right)$and vinylamine $\left(\mathrm{NH}_{2} \mathrm{CCH}_{2}^{+}\right)$cations $(\mathrm{m} / \mathrm{z}=42 \mathrm{amu})$ become more stable than their original forms. The intramolecular hydrogen transfer between them is an exact analogue to the previously studied imine/enamine tautomerisation processes. ${ }^{57}$

The analysis of the slopes in the detected islands provide information of the fragmentation mechanisms ${ }^{58}$ (see $\mathrm{ESI} \dagger$ for details): the pair $\left(43^{+} / 45^{+}\right)$corresponds to the fragments $\mathrm{NH}_{2} \mathrm{CHCH}_{2}{ }^{+}$ or $\mathrm{NH}_{2} \mathrm{CCH}_{3}^{+}$with $\mathrm{COOH}^{+}$. A slope of -1.02 is expected considering this mechanism. Quantum chemistry calculations are thus in a good agreement with the measured slope. For the pairs $\left(42^{+} / 45^{+}\right)$and $\left(41^{+} / 45^{+}\right)$, in which two or three hydrogen atoms are emitted from $\mathrm{NH}_{2} \mathrm{CHCH}_{3}{ }^{+}(\mathrm{m} / z=44 \mathrm{amu})$, we obtained the slopes -1.05 $(-2 \mathrm{H})$ and $-1.07(-3 \mathrm{H})$ with the computed mechanisms. They are also in agreement with the experimental ones taking into account the experimental uncertainties. The conclusion is that computed pathways are consistent with the experimental measurements (see Table $\mathrm{S} 1$ in the ESI $\dagger$ ).

Complementary information on the fragmentation of $\mathrm{NH}_{2} \mathrm{CHCH}_{3}{ }^{+}$is given in the right part of Fig. 8. The pathway after $\mathrm{CH}_{2}$ emission leaves $\mathrm{NH}_{2} \mathrm{CH}_{2}^{+}$, a very stable ion in coincidence with $\mathrm{COOH}^{+}\left(30^{+} / 45^{+}\right)$. Further emission of hydrogen produces $\mathrm{NH}_{2} \mathrm{CH}^{+} / \mathrm{COOH}^{+}$and $\mathrm{NHCH}^{+} / \mathrm{COOH}^{+}$, where the latter channel (direct $\mathrm{H}_{2}$ emission) is much lower in energy than the $\mathrm{H}$ emission (which appears $1.3 \mathrm{eV}$ above the entrance channel). Accordingly, only the one corresponding to hydrogen molecule emission is observed in the experiment, pair $\left(28^{+} / 45^{+}\right)$(see Fig. 6b).

Other fragments observed in the correlation with $\mathrm{COOH}^{+}$are $m / z=27$ and $m / z=18$ amu (see Table S1 in the ESI $\dagger$ ). The first one is associated with the fragmentation channel shown in the left part of Fig. 8: $\mathrm{COOH}^{+}+\mathrm{NH}_{3} \mathrm{CHCH}_{2}^{+} \rightarrow \mathrm{COOH}^{+}+\mathrm{NH}_{3}+\mathrm{CHCH}_{2}{ }^{+}$.
This channel appears in competition with the one related to $\left(18^{+} / 45^{+}\right)$i.e. $\mathrm{COOH}^{+}+\mathrm{NH}_{3} \mathrm{CHCH}_{2}^{+} \rightarrow \mathrm{COOH}^{+}+\mathrm{NH}_{4}^{+}+\mathrm{CHCH}$. The latter explains the correlation $18^{+} / 45^{+}$(barrier on the PES at $20.74 \mathrm{eV})$. Both coincidence measurements $\left(18^{+} / 45^{+}\right.$and $\left.27^{+} / 45^{+}\right)$ show very similar relative intensities (see Table S1 in ESI $\dagger$ ). Accordingly, both channels require similar fragmentation energies (Fig. 8). The pairs $\left(28^{+} / 45^{+}\right)$and $\left(27^{+} / 45^{+}\right)$correspond to the loss of two or three hydrogen atoms from $\mathrm{NH}_{2} \mathrm{CH}_{2}{ }^{+}$. The theoretical slopes of the three pairs $\left(27^{+} / 45^{+}\right),\left(28^{+} / 45^{+}\right)$and $\left(30^{+} / 45^{+}\right)$are respectively $-1.63,-1.57$ and -1.47 , which is also in agreement with the experimentally measured slopes (see table in ESI $\dagger$ ). They correspond to Coulomb explosion with $\mathrm{C}_{\text {carboxylic }}-\mathrm{C}_{\alpha}$ bond breaking followed by emission of neutral moieties.

Further fragmentation of $\mathrm{NH}_{3} \mathrm{CHCH}_{2}{ }^{+}$, proposed in Fig. 8, provides the mechanisms to explain the peaks related to $\mathrm{m} / \mathrm{z}=$ 15, 16 and 17 amu in coincidence with $\mathrm{COOH}^{+}(m / z=45 \mathrm{amu})$. In the same figure we can also observe the pathway leading to the quite stable protonated ethylenimine (EI) cyclic cation $\left(\mathrm{NH}_{2} \mathrm{CH}_{2} \mathrm{CH}_{2}{ }^{+}\right)$, which is a three-membered ring derivative of the monomer employed in the polymerisation by a cationic stepwise mechanism of the imino group. ${ }^{59}$ Moreover, it is well known that ethylenimine and its derivatives cause degradation of $\mathrm{DNA}^{60}$ and in reaction with 2-deoxy-D-ribose produce $\mathrm{H}_{2} \mathrm{O}_{2}$, a strong oxidative compound. ${ }^{59}$ It is thus reasonable to propose the protonated EI cation as a dangerous and active compound produced with a relatively strong intensity in the fragmentation of $\beta$-alanine dication.

\section{(b) $\mathrm{C}_{\alpha}-\mathrm{C}_{\beta}$ bond breaking}

$\mathrm{C}_{\alpha}-\mathrm{C}_{\beta}$ bond cleavage gives $\mathrm{NH}_{2} \mathrm{CH}_{2}{ }^{+}+\mathrm{CH}_{2} \mathrm{COOH}^{+}$(expected coincidence $30^{+} / 59^{+}$). However, in the experiment we do not 


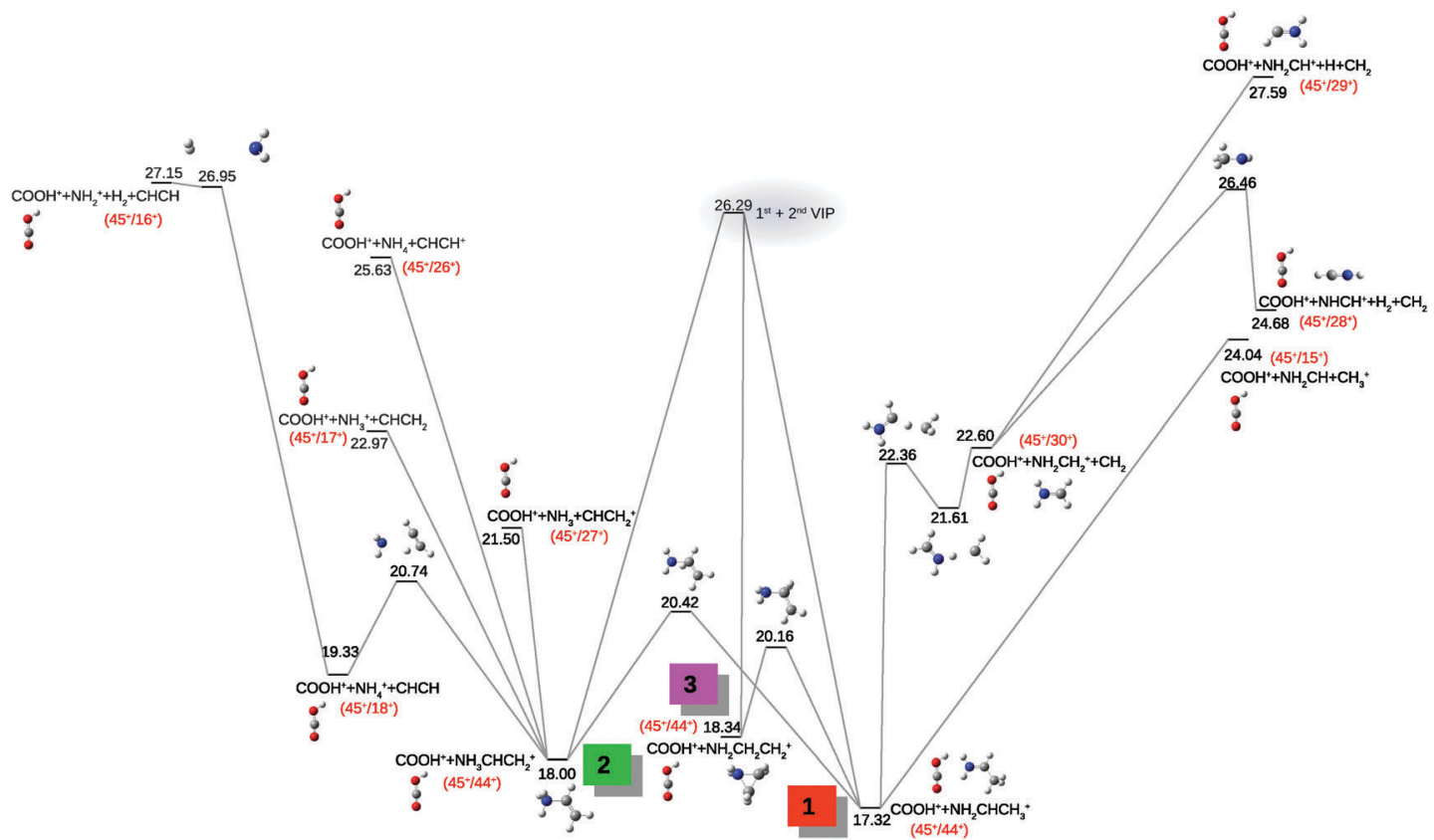

Fig. 8 Further fragmentation due to $C_{\text {carboxyl }}-C_{\alpha}$ bond breaking are shown leading to charged fragments: $m / z=45$ amu with other heavy fragments $(\mathrm{m} / \mathrm{z}=30,28,27,26,18,17,16$ and $15 \mathrm{amu})$. Detailed information in the caption of Fig. 7.

observe the signal at $m / z=59$ amu (see Fig. 1). This cation can easily break by losing $\mathrm{CH}_{2}$ or $\mathrm{OH}$ without barriers. Indeed, the relatively low energies calculated for the fragments produced in the corresponding pathways, $\mathrm{HOCH}_{2} \mathrm{CO}^{+}$or $\mathrm{CH}_{2} \mathrm{COOH}^{+}$, and the absence of a peak at $m / z=59 \mathrm{amu}$ in the experiments, allow us to conclude that the fragment at $m / z=59$ amu undergoes further fragmentation, in these kinetically favourable processes, leading to signals at $\left(30^{+} / 42^{+}\right)$and $\left(30^{+} / 45^{+}\right)$(see Fig. 9 for the corresponding mechanisms). The observation of the signal at $\left(30^{+} / 42^{+}\right)$also indicates that the molecule has enough internal energy to break leading to $\mathrm{NH}_{2} \mathrm{CH}_{2}{ }^{+}+\mathrm{CH}_{2} \mathrm{CO}^{+}+\mathrm{OH}$. These species can be obtained in two different pathways. (i) $\mathrm{OH}$ emission followed by Coulomb repulsion $\left[\beta\right.$-alanine ${ }^{2+} \rightarrow \mathrm{NH}_{2} \mathrm{CH}_{2} \mathrm{CH}_{2} \mathrm{CO}^{2+}+$ $\mathrm{OH} \rightarrow \mathrm{NH}_{2} \mathrm{CH}_{2}{ }^{+}+\mathrm{CH}_{2} \mathrm{CO}^{+}+\mathrm{OH}$ ], (ii) first Coulomb explosion $\left[\beta\right.$-alanine $\left.{ }^{2+} \rightarrow \mathrm{NH}_{2} \mathrm{CH}_{2}{ }^{+}+\mathrm{CH}_{2} \mathrm{COOH}^{+}\right]$and then emission of neutral OH $\left[\mathrm{NH}_{2} \mathrm{CH}_{2}^{+}+\mathrm{CH}_{2} \mathrm{CO}^{+}+\mathrm{OH}\right]$. The associated computed slopes are -1 and -0.71 , respectively. The experimentally measured slope suggests first emission of neutral $\mathrm{OH}$ leading to $\mathrm{NH}_{2} \mathrm{CH}_{2} \mathrm{CH}_{2} \mathrm{CO}^{2+}$ followed by Coulomb repulsion producing $\mathrm{NH}_{2} \mathrm{CH}_{2}{ }^{+}+\mathrm{CH}_{2} \mathrm{CO}^{+}$(see pathway in Fig. 9).

The right part of Fig. 9 shows that the evaporation of $\mathrm{CH}_{2}$ from $\mathrm{CH}_{2} \mathrm{COOH}^{+}$leads to the coincidence $\left(30^{+} / 45^{+}\right)$. Further fragmentation of $\mathrm{NH}_{2} \mathrm{CH}_{2}{ }^{+}$by emission of $\mathrm{H}_{2}$ leads to $\mathrm{NHCH}^{+}$ in coincidence with $\mathrm{COOH}^{+}$, island $\left(28^{+} / 45^{+}\right)$.

The most intense island observed in the experiment is $\mathrm{m} / \mathrm{z}=$ $30 \mathrm{amu}\left(\mathrm{NH}_{2} \mathrm{CH}_{2}{ }^{+}\right)$in correlation with $m / z=42 \mathrm{amu}\left(\mathrm{CH}_{2} \mathrm{CO}^{+}\right)$ coming from $\mathrm{C}_{\alpha}-\mathrm{C}_{\beta}$ bond breaking. For the first fragment we observe similar many body fragmentation processes as the one described above, i.e. loss of one or two hydrogen atoms from $\mathrm{NH}_{2} \mathrm{CH}_{2}^{+}$leading to the pairs $\left(29^{+} / 42^{+}\right)$and $\left(28^{+} / 42^{+}\right)$, respectively. In Fig. 6b, we can see that the three pairs have an experimental slope very close to -1 . This is an indication that the molecular

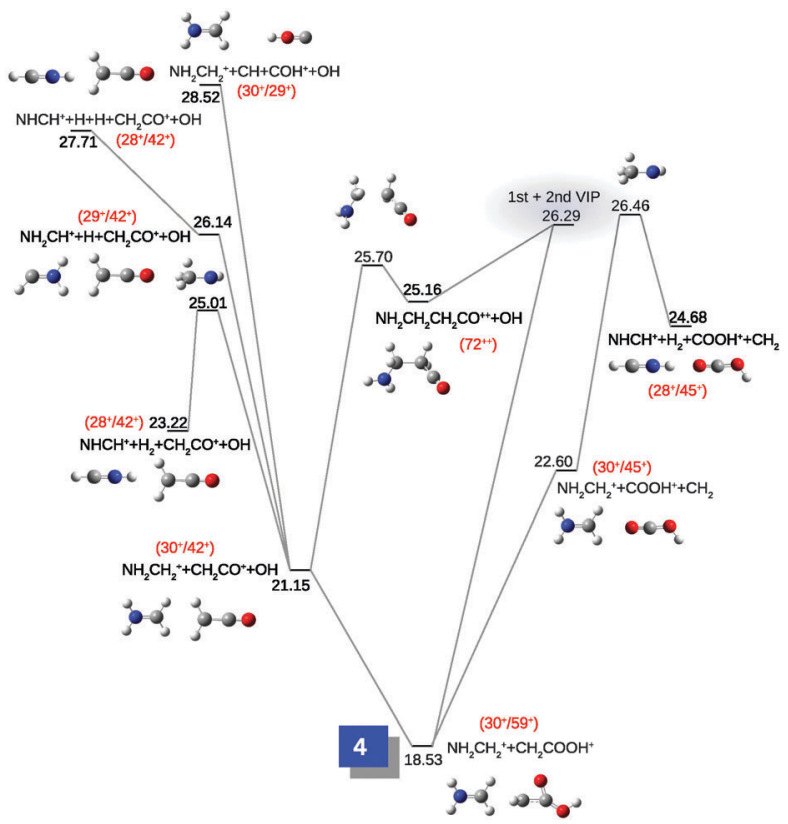

Fig. 9 Stationary points of the potential energy surface corresponding to $\mathrm{C}_{\alpha}-\mathrm{C}_{\beta}$ bond breaking. Correlation notation is included, e.g. $\left(44^{+} / 45^{+}\right)$. Detailed information in the caption of Fig. 7.

dication $\beta$-alanine ${ }^{2+}$ first loses a neutral $\mathrm{OH}$ fragment and then splits into two singly charged cations. Another group of islands involving the most prominent cation $\mathrm{NH}_{2} \mathrm{CH}_{2}^{+}$is observed in correlation with the $\mathrm{COOH}^{+}$fragment.

Interesting molecular structures are observed for the spectra associated with the peaks at $m / z=44,43,42$ and $41 \mathrm{amu}$ (see Fig. 10). These cations present resonant structures with $\pi$ delocalised electrons or strong $\mathrm{N}=\mathrm{C}, \mathrm{N} \equiv \mathrm{C}$ bonds. The associated exit 

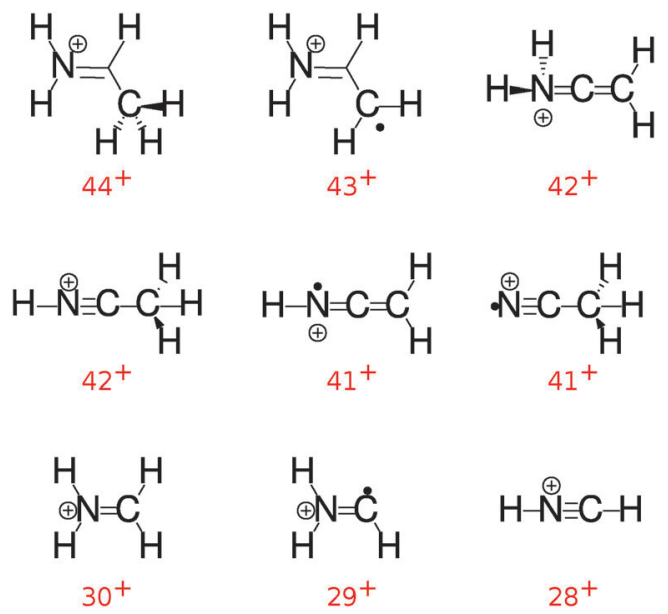

Fig. 10 Schematic structures of molecular cations with $m / z=44,43,42$, 41, 30, 29 and 28 amu, respectively.

channels appear a few eV below the entrance channel due to the high stability of such species (see Fig. 7). However, this trend is not observed for the row at $m / z=30,29$ and 28 amu (see Fig. 6b). The lack of the peak at $m / z=29$ amu in the experiment is caused by the fact that this molecule is a radical and its relative stability is much lower than the corresponding closed shell molecules $(m / z=30,28$ amu) (see Fig. 9).

\section{(c) $\mathbf{H}$ migration}

We now focus on the exit channels produced after the most important isomerisation mechanism observed in the dynamics simulations: formation of the doubly charged geminal diol $\mathrm{NH}_{2} \mathrm{CHCH}_{2} \mathrm{C}(\mathrm{OH})_{2}{ }^{2+}$. In particular, we analyse two mechanisms: (i) Coulomb explosion after $\mathrm{H}$ transfer (see Fig. 11) and (ii) emission of neutral fragments leading to stable dicationic species (see Fig. 12). Both mechanisms are in competition with the rest of the processes but occur with lower probability, similar to our previous observations for glycine. ${ }^{21}$

Fragmentation of $\mathrm{diol}^{2+}$ due to the Coulomb explosion implies three exit channels: $\mathrm{NH}_{2} \mathrm{CHCH}_{2} \mathrm{CO}^{+}+\mathrm{H}_{2} \mathrm{O}^{+}\left(71^{+} / 18^{+}\right)$, $\mathrm{NH}_{2} \mathrm{CHCHCOH}^{+}+\mathrm{H}_{2} \mathrm{O}^{+}\left(71^{+} / 18^{+}\right)$and $\mathrm{NH}_{2} \mathrm{CHCHCO}^{+}+\mathrm{H}_{3} \mathrm{O}^{+}$ $\left(70^{+} / 19^{+}\right)$. A subsequent fragmentation pathway of $\mathrm{NH}_{2} \mathrm{CHCH}_{2} \mathrm{CO}^{+}$ has also been calculated leading to $\mathrm{NH}_{2} \mathrm{CHCH}_{2}{ }^{+}\left(43^{+} / 18^{+}\right)$with the emission of a neutral carbon monoxide molecule. Fig. 11 shows the corresponding pathways in the PES. All of them are below the entrance channel but they can be produced only if one considers atomic rearrangement (even double $\mathrm{H}$ transfer) before fragmentation. The corresponding correlation islands present low relative intensity in the experiment and, accordingly, in the AIMD simulations the probability to occur is very small.

Hydrogen migration can be also followed by emission of neutral fragments. Indeed, the stable small dicationic molecules detected in the experiment are produced after emission of neutral species: $\mathrm{H}_{2} \mathrm{O}, \mathrm{H}, \mathrm{H}_{2}, \mathrm{CH}_{2}, \mathrm{CO}, \mathrm{CO}_{2}$ or $\mathrm{CH}_{2} \mathrm{CO}$ from doubly charged diol. The study of this part of the PES is presented in Fig. 12 and it explains the different chemical mechanisms leading to molecular dications experimentally detected at signals: $m / z=35.5,35,34.5,34,21.5,21,20.5,20$ and 14.5 amu

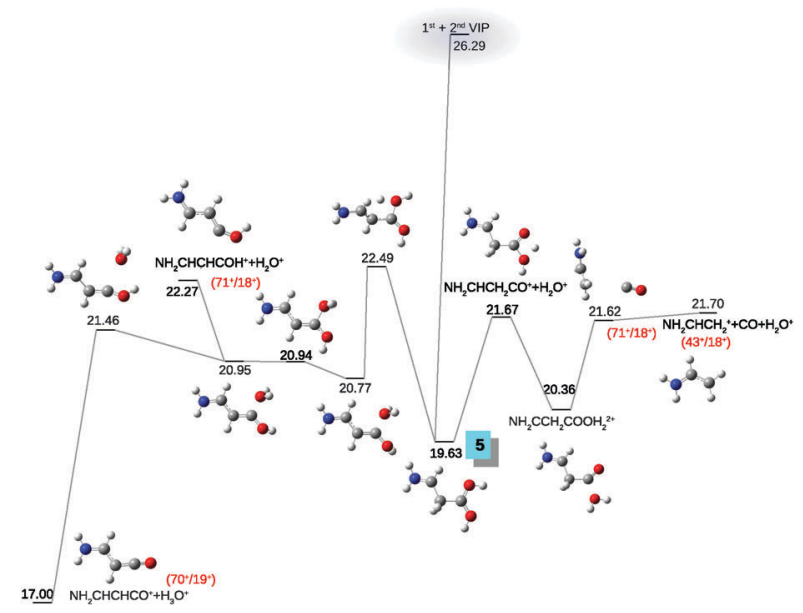

Fig. 11 Stationary points of the potential energy surface corresponding to $\mathrm{H}$ migration and further Coulomb explosion, leading to two charged fragments. Correlation notation is also included, e.g. $\left(71^{+} / 18^{+}\right)$. Detailed information in the caption of Fig. 7.

(see zooms-in in Fig. 1). The pathways explaining these peaks come from the key structure $\mathrm{NH}_{2} \mathrm{CHCH}_{2} \mathrm{CO}^{2+}$ produced after neutral $\mathrm{H}_{2} \mathrm{O}$ loss from the doubly charged diol, through the formation of the intermediate, weakly bonded complex $\mathrm{NH}_{2} \mathrm{CHCH}_{2} \mathrm{COH}_{2} \mathrm{O}^{2+} \cdot \mathrm{NH}_{2} \mathrm{CHCH}_{2} \mathrm{CO}^{2+}$ is a very stable acylium ion showing a resonant structure. The dehydration mechanism does not involve the amine group ${ }^{61}$ and energetically is more preferable than splitting the charge into two fragments. This is the reason why in the experiment we almost do not observe the pair $\left(71^{+} / 18^{+}\right)$in the coincidence map (even if this channel appears at lower energy than the entrance one). Starting from the key structure $\mathrm{NH}_{2} \mathrm{CHCH}_{2} \mathrm{CO}^{2+}$ the loss of $\mathrm{H}, \mathrm{H}_{2}, \mathrm{CO}$ and $\mathrm{CH}_{2} \mathrm{CO}$ explain the peaks at 35, 34.5, 21.5 and 14.5 amu: $\mathrm{NH}_{2} \mathrm{CHCHCO}^{2+}, \mathrm{NHCCH}_{2} \mathrm{CO}^{2+}, \mathrm{NH}_{2} \mathrm{CHCH}_{2}{ }^{2+}$ and $\mathrm{NH}_{2} \mathrm{CH}^{2+}$, respectively. A subsequent emission of $\mathrm{H}$ and $\mathrm{H}_{2}$ from these dications explain the rest of peaks corresponding to doubly charged molecules: $(\mathrm{m} / \mathrm{z}=34,21,20.5$ and $20 \mathrm{amu})$. Moreover, charge separation of the key structure $\mathrm{NH}_{2} \mathrm{CHCH}_{2} \mathrm{CO}^{2+}$ can explain the island at $29^{+} / 42^{+}$(two body charge separation slope equals -1): $(\beta \text {-alanine })^{2+} \rightarrow \operatorname{diol}^{2+} \rightarrow \mathrm{NH}_{2} \mathrm{CHCH}_{2} \mathrm{CO}^{2+}+\mathrm{H}_{2} \mathrm{O} \rightarrow$ $\mathrm{NH}_{2} \mathrm{CHCH}^{+}+\mathrm{COH}^{+}+\mathrm{H}_{2} \mathrm{O}$. The study of the PES also predicts an alternative mechanism for the formation of $\mathrm{NH}_{2} \mathrm{CHCH}_{2}{ }^{2+}$ $(\mathrm{m} / \mathrm{z}=21.5 \mathrm{amu})$, avoiding dehydration from the weakly bounded intermediate complex. The dication of $\operatorname{diol}^{2+}$ also undergoes dehydrogenation and simultaneously decarboxylation in a one-step three body fragmentation mechanism: $\mathrm{NH}_{2} \mathrm{CHCH}_{2} \mathrm{C}(\mathrm{OH})_{2}{ }^{2+} \rightarrow$ $\mathrm{NH}_{2} \mathrm{CHCH}_{2}{ }^{2+}+\mathrm{CO}_{2}+\mathrm{H}_{2}$. The exit channel corresponding to this mechanism is energetically more favourable than most of the previous ones proposed to produce dications. Further subsequent fragmentation of the produced doubly charged molecule $\left(\mathrm{NH}_{2} \mathrm{CHCH}_{2}{ }^{2+}\right)$ by loosing $\mathrm{H}, \mathrm{H}_{2}, \mathrm{CH}_{2}$ are alternative paths to explain the peaks at 21, 20.5, 20 and $14.5 \mathrm{amu}$, respectively.

\section{(d) $\mathrm{OH}$ migration}

In the ion-induced fragmentation of glycine, hydrogen migration was observed in competition with direct Coulomb explosion and 


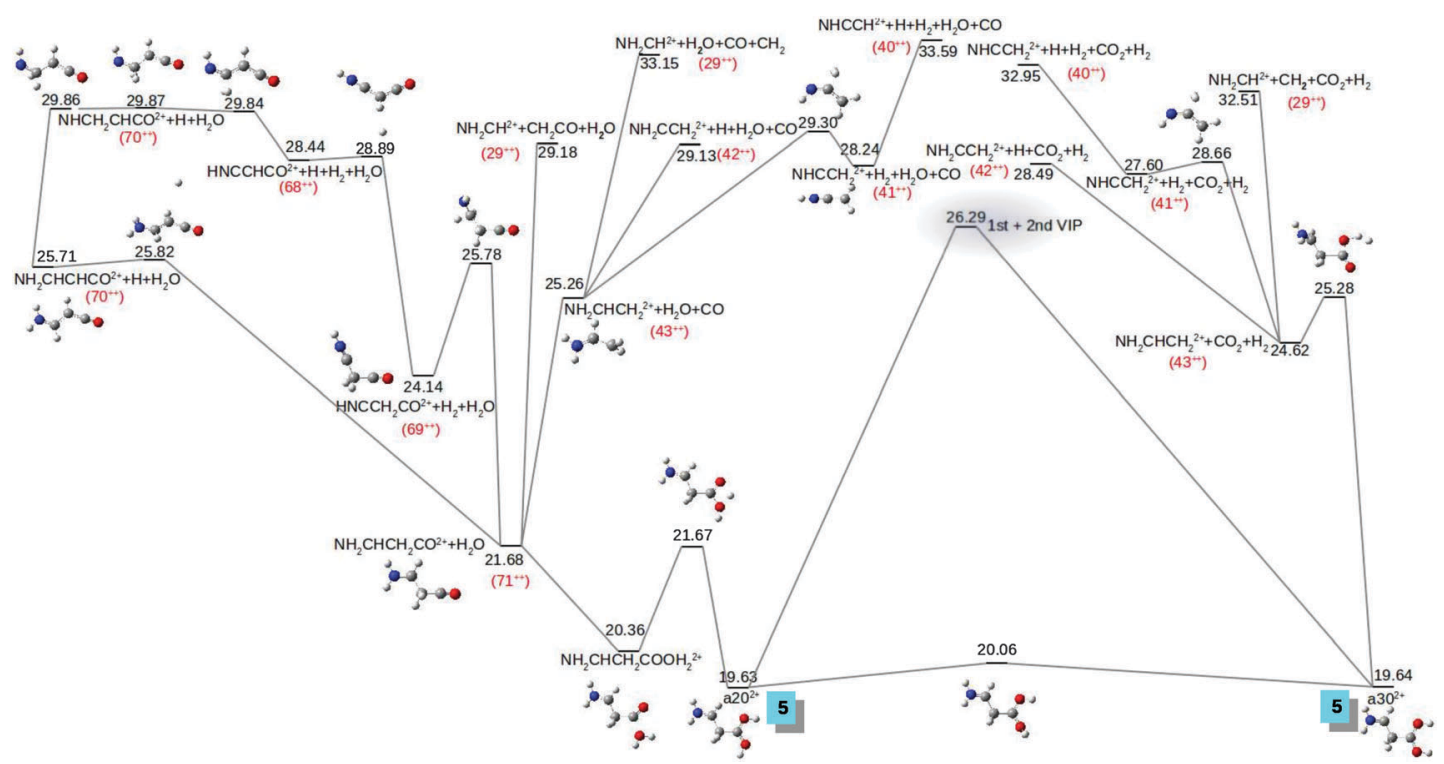

Fig. 12 Stationary points of the potential energy surface corresponding to $\mathrm{H}$ migration and further emission of neutral species, leading to doubly charged fragments. Mass spectrum notation is also included, e.g. $71^{++}$corresponds to $\mathrm{m} / \mathrm{z}=35 \mathrm{amu}$. Detailed information in the caption of Fig. 7 .

was essential to understand the fragmentation dynamics. ${ }^{21}$ For $\beta$-alanine our molecular dynamics simulations have shown a quite probable fragmentation pathway in competition with $\mathrm{H}$ migration and Coulomb explosion: hydroxyl group migration accompanied with emission of neutral $\mathrm{CO}$ and leading to two singly charged fragments $\left(\mathrm{NH}_{2} \mathrm{CH}_{2}{ }^{+}\right.$and $\left.\mathrm{CH}_{2} \mathrm{OH}^{+}\right)$. This channel appears at very low energy in the PES (see Fig. 13) and is assigned to the correlation $\left(30^{+} / 31^{+}\right)$measured with a very strong relative intensity (see Fig. $6 \mathrm{c}$ and Table S1 in ESI $\dagger$ ). Moreover, from the entropic point of view it is more favourable than other channels. The computed mechanism reveals that the metastable $\mathrm{HOCH}_{2} \mathrm{CO}^{+}$structure is involved before the loss of a neutral carbon monoxide and finally producing the detected ions: $\mathrm{NH}_{2} \mathrm{CH}_{2}{ }^{+}$and $\mathrm{HOCH}_{2}{ }^{+}$. The metastable structure observed in

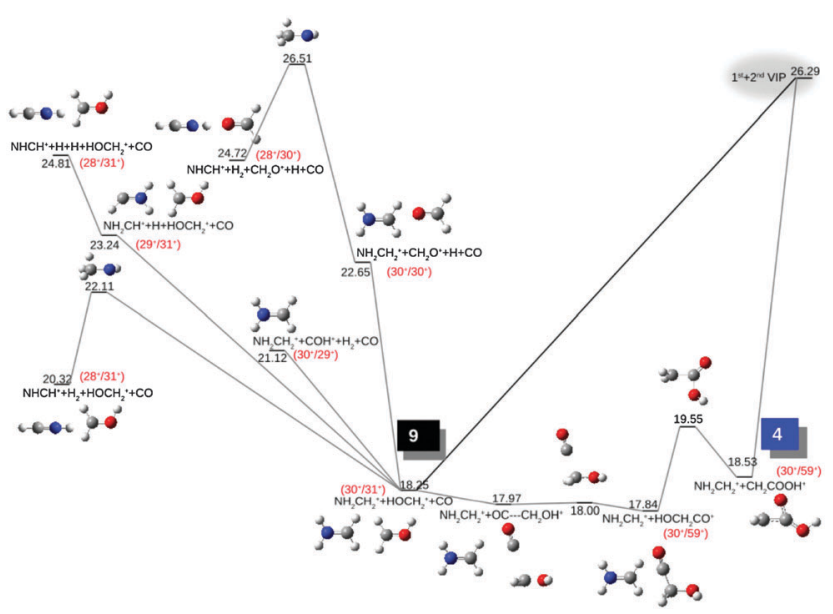

Fig. 13 Stationary points of the potential energy surface corresponding to hydroxyl group migration and further fragmentation pathways. Coincidence notation is also included, e.g. $\left(30^{+} / 59^{+}\right)$. Detailed information in the caption of Fig. 7. the molecular dynamics $\left(\mathrm{HOCH}_{2} \mathrm{CO}^{+}\right)$is an isomer of a $\mathrm{CO}$ protonated $\alpha$-lactone. ${ }^{62}$ These species were previously observed in the gas phase reactions of amino acids with the nitrosonium ion $\left(\mathrm{NO}^{+}\right) \cdot{ }^{63}$ Moreover, previous studies have demonstrated that the open carbo-cation $\mathrm{CH}_{2} \mathrm{COOH}^{+}$is not a saddle point on the PES. ${ }^{64,65}$ AIMD simulations show that $\mathrm{CH}_{2} \mathrm{COOH}^{+}$easily collapses to a $\mathrm{CO}$ protonated $\alpha$-lactone (a transient species previously described in mass spectrometry experiments ${ }^{66}$ ), and the ring opens to form a more stable cation $\left(\mathrm{OCCH}_{2} \mathrm{OH}^{+}\right)$. Further fragmentation of this cation leads to hydroxymethyl $\left(\mathrm{CH}_{2} \mathrm{OH}^{+}\right)$or to formaldehyde $\left(\mathrm{CH}_{2} \mathrm{O}^{+}\right)$cations. The latter one was also previously detected. ${ }^{67}$ Interestingly, both species have been identified from spectral lines in the interstellar medium ${ }^{68}$ and reactions between them can produce glycol aldehyde, acetic acid and methyl formate. ${ }^{69}$ On the other hand, the hydroxymethyl cation $(\mathrm{m} / \mathrm{z}=31 \mathrm{amu})$ was previously observed only in the single ionisation process after direct side chain bond breaking of serine. ${ }^{16}$

The fragmentation mechanism presented here is the only possibility to explain the coincidence island at $\left(30^{+} / 31^{+}\right)$. For the double ionisation process the driving force for this mechanism is the high stability of the products $\mathrm{NH}_{2} \mathrm{CH}_{2}{ }^{+}+\mathrm{HOCH}_{2}{ }^{+}+\mathrm{CO}$ $(18.25 \mathrm{eV})$ with a relative energy $8 \mathrm{eV}$ lower than the entrance channel and much lower than other channels with different charge distributions (e.g. $\mathrm{NH}_{2} \mathrm{CH}_{2}^{+}+\mathrm{HOCH}_{2}+\mathrm{CO}^{+}$appears at $24.72 \mathrm{eV})$. The iminium cation $\left(\mathrm{NH}_{2} \mathrm{CH}_{2}{ }^{+}\right)$possesses a strong hydride ion affinity. ${ }^{70}$ Thus, in the first fs of the fragmentation the amino methyl cation can attract the hydride group from the other fragment $\mathrm{CH}_{2} \mathrm{COOH}^{+}$, causing the reorganisation of the geometry and allowing the movement of the $\mathrm{OH}$ group. This is indeed, the third most probable channel and leads to $\mathrm{NH}_{2} \mathrm{CH}_{2}{ }^{+}+$ $\mathrm{CO}+\mathrm{CH}_{2} \mathrm{OH}^{+}$(see Fig. 5b). Further fragmentation in this channel corresponds to the emission of neutral hydrogen molecule from $\mathrm{NH}_{2} \mathrm{CH}_{2}{ }^{+}$and leads to the coincidence measurement with $28^{+} / 31^{+}\left(\mathrm{NHCH}^{+} / \mathrm{HOCH}_{2}{ }^{+}\right)$. The presence of the pairs 
$\left(30^{+} / 31^{+}\right)$and $\left(28^{+} / 31^{+}\right)$(see Fig. $6 \mathrm{c}$.) can not be explained by the direct bond fragmentation of the molecular dication $\beta$-alanine ${ }^{2+}$ and must involve a rearrangement after Coulomb explosion. This $\mathrm{OH}$ migration is about three times slower than ultrafast $\mathrm{H}$ transfer and appears at around $120 \mathrm{fs}$ of the simulations (see Fig. 4). Moreover, this mechanism can be considered as one of the dominant at longer timescales due to the subsequent fragmentation of the products of mechanism (4). The exit channel after process (9) is energetically more favourable than the exit channel after process (4). Thus, at longer simulation time, products from (4) can easily evolve to products from (9) (see Fig. 13). Indeed the second most intense coincidence island corresponds to the products of mechanism (9): $\mathrm{NH}_{2} \mathrm{CH}_{2}^{+}+\mathrm{CH}_{2} \mathrm{OH}^{+}\left(30^{+} / 31^{+}\right)$.

\section{Conclusions}

We have studied the fragmentation dynamics and different de-excitation pathways characterising the decay of excited doublycharged $\beta$-alanine molecules in the gas phase. Experimentally, excited molecular dications were produced in collisions with $\mathrm{O}^{6+}$ ions and the fragments were identified by coincidence time-offlight mass spectrometry allowing to determine the fragmentation dynamics and highlighting the presence of new ionic species. Theoretically, we have found in ab initio molecular dynamics simulations that three types of processes occur in competition: (i) Coulomb explosion leads to the detection in correlation of two singly charged fragments; (ii) the formation of small stable dications produced by evaporation of neutral fragments following ultrafast intramolecular hydrogen migration ( 40 fs); (iii) Coulomb explosion followed by hydroxyl group migration. The third process has not been previously reported and is expected to occur in other biomolecules. The good agreement between our simulation in the electronic ground state with the experimental measurements also sheds light on the charge state and excitation energy of the molecule after ionisation with highly charged ions and allows us to confirm that the excitation energy is quickly distributed over the vibrational degrees of freedom of the molecule.

\section{Acknowledgements}

The experimental studies have been performed at the lowenergy ion beam facility ARIBE at GANIL (Caen, France). We thank the support given by the CIMAP team. We acknowledge the generous allocation of computer time at the Centro de Computación Cientfica at the Universidad Autónoma de Madrid (CCC-UAM). Financial support received from the CNRS PICS05356 program, the ANR Programme Blanc PIBALE/ANR-09BLAN-013001 and the Conseil Régional de Basse-Normandie is gratefully acknowledged. Research was conducted in the scope of the International Associated Laboratory (LIA) "Fragmentation DYNAmics of complex MOlecular systems - DYNAMO” and in the COST actions XLIC (CM1204) and Nano-IBCT (MP1002). Work was partially supported by the projects FIS2013-42002-R and CTQ2013-43698-P (MINECO), and NANOFRONTMAG (CAM). D.G.P. acknowledges the support of the Erasmus Mundus program of the European Union (FPA 2010-0147) and the FPI doctorate grant of the Universidad Autónoma de Madrid. S. D.-T. gratefully acknowledges the "Ramón y Cajal" program of the Spanish Ministerio de Educación y Ciencia.

\section{References}

1 G. A. Olah, A. Germain, H. C. Lin and D. A. Forsyth, J. Am. Chem. Soc., 1975, 97, 2928-2929.

2 G. A. Olah, Angew. Chem., Int. Ed., 1993, 32, 767-788.

3 C. L. Ricketts, D. Schröder, C. Alcaraz and J. Roithová, Chem. - Eur. J., 2008, 14, 4779-4783.

4 J. Roithová and D. Schröeder, J. Am. Chem. Soc., 2006, 128, 4208-4209.

5 P. Ehrenfreund, D. P. Glavin, O. Botta, G. Cooper and J. L. Bada, Proc. Natl. Acad. Sci. U. S. A., 2001, 98, 2138-2141.

6 J. H. Kang, K. S. Kim, S. Y. Choi, H. Y. Kwon, M. H. Won and T.-C. Kang, Biochim. Biophys. Acta, Gen. Subj., 2002, 1570, 89-96.

7 A. Gil, S. Simon, L. Rodríguez-Santiago, J. Bertrán and M. Sodupe, J. Chem. Theory Comput., 2007, 3, 2210-2220.

8 A. Gil, S. Simon, M. Sodupe and J. Bertrán, Chem. Phys. Lett., 2008, 451, 276-281.

9 S. Naumov, I. Janovský, W. Knolle and R. Mehnert, Macromol. Chem. Phys., 2003, 204, 2099-2104.

10 R. N. Loeppky and C. J. Michejda, ACS Symp. Ser., 1994, 553, 1-18.

11 J. Casado, A. Castro, J. R. Leis, M. Mosquera and M. E. Pena, J. Chem. Soc., Perkin Trans. 2, 1985, 1859-1864.

12 R. Gil, J. Casado and C. Izquierdo, Int. J. Chem. Kinet., 1994, 26, 1167-1178.

13 G. A. Olah, J. Shih and G. K. S. Prakash, Helv. Chim. Acta, 1983, 66, 1028-1030.

14 S. Bari, P. Sobociński, J. Postma, F. Alvarado, R. Hoekstra, V. Bernigaud, B. Manil, J. Rangama, B. Huber and T. Schlathölter, J. Chem. Phys., 2008, 128, 074306.

15 S. Bari, F. Alvarado, J. Postma, P. Sobociński, R. Hoekstra and T. Schlathölter, Eur. Phys. J. D, 2008, 51, 81-87.

16 S. Simon, A. Gil, M. Sodupe and J. Bertrán, THEOCHEM, 2005, 727, 191-197.

17 P. Sobociński, S. Bari, J. Postma, F. Alvarado, R. Hoekstra, B. Manil, J. Rangama, V. Bernigaud, B. Huber and T. Schlathölter, J. Phys.: Conf. Ser., 2008, 101, 012006.

18 H.-W. Jochims, M. Schwell, J.-L. Chotin, M. Clemino, F. Dulieu, H. Baumgärtel and S. Leach, Chem. Phys., 2004, 298, 279-297.

19 S. Bari, F. Alvarado, J. Postma, P. Sobociński, R. Hoekstra and T. Schlathölter, Eur. Phys. J. D, 2008, 51, 81-87.

20 M. Capron, S. Díaz-Tendero, S. Maclot, A. Domaracka, E. Lattouf, A. Ławicki, R. Maisonny, J.-Y. Chesnel, A. Méry, J.-C. Poully, J. Rangama, L. Adoui, F. Martín, M. Alcamí, 
P. Rousseau and B. A. Huber, Chem. - Eur. J., 2012, 18, 9321-9332.

21 S. Maclot, D. G. Piekarski, A. Domaracka, A. Méry, V. Vizcaino, L. Adoui, F. Martín, M. Alcamí, B. A. Huber, P. Rousseau and S. Díaz-Tendero, J. Phys. Chem. Lett., 2013, 4, 3903-3909.

22 M. Dizdaroglu, Free Radicals Biol. Med., 1991, 10, 225-242.

23 P. Riley, Int. J. Radiat. Biol., 1994, 65, 27-33.

24 J. Cadet, T. Douki and J.-L. Ravanat, Free Radicals Biol. Med., 2010, 49, 9-21.

25 S. S. Wallace, Radiat. Res., 1998, 150, S60-S79.

26 L. Sanche, Eur. Phys. J. D, 2005, 35, 367-390.

27 C. V. Parast, K. K. Wong, S. A. Lewisch, J. W. Kozarich, J. Peisach and R. S. Magliozzo, Biochemistry, 1995, 34, 2393-2399.

28 P. Swiderek, Angew. Chem., Int. Ed., 2006, 45, 4056-4059.

29 B. Boudaïffa, P. Cloutier, D. Hunting, M. Huels and L. Sanche, Science, 2000, 287, 1658-1660.

30 M. H. Holzscheiter, N. Bassler, M. Dosanjh, B. S. Srensen and J. Overgaard, Radiother. Oncol., 2012, 105, 1-3.

31 P. Bolognesi, P. O'Keeffe and L. Avaldi, in Radiation Damage in Biomolecular Systems, ed. G. Garcá Gómez-Tejedor and M. C. Fuss, Springer, Netherlands, 2012, pp. 165-176.

32 M. Durante and J. S. Loeffler, Nat. Rev. Clin. Oncol., 2010, 7, 37-43.

33 COST Action MP1002: Nano-IBCT: Nano-scale Insight into Ion beam cancer therapy, 2010, http://www.cost.eu/domains_ actions/mpns/Actions/MP1002.

34 T. Toraya, Chem. Rev., 2003, 34, 2095-2127.

35 K. L. Brown, Chem. Rev., 2005, 36, 2075-2149.

36 D. M. Smith, B. T. Golding and L. Radom, J. Am. Chem. Soc., 2001, 123, 1664-1675.

37 T. Toraya, K. Yoshizawa and T. Kamachi, J. Am. Chem. Soc., 2004, 126, 16207-16216.

38 T. Kamachi, T. Toraya and K. Yoshizawa, Chem. - Eur. J., 2007, 13, 7864-7873.

39 A. D. Becke, J. Chem. Phys., 1993, 98, 5648-5652.

40 C. Lee, W. Yang and R. G. Parr, Phys. Rev. B: Condens. Matter Mater. Phys., 1988, 37, 785-789.

41 M. Ramek and V. K. W. Cheng, Int. J. Quantum Chem., 1992, 44, 15-26.

42 K. Fukui, Acc. Chem. Res., 1981, 14, 363-368.

43 H. B. Schlegel, J. M. Millam, S. S. Iyengar, G. A. Voth, A. D. Daniels, G. E. Scuseria and M. J. Frisch, J. Chem. Phys., 2001, 114, 9758-9763.

44 S. S. Iyengar, H. B. Schlegel, J. M. Millam, G. A. Voth, G. E. Scuseria and M. J. Frisch, J. Chem. Phys., 2001, 115, 10291-10302.

45 H. B. Schlegel, S. S. Iyengar, X. Li, J. M. Millam, G. A. Voth, G. E. Scuseria and M. J. Frisch, J. Chem. Phys., 2002, 117, 8694-8704.

46 S. S. Iyengar, H. B. Schlegel and G. A. Voth, J. Phys. Chem. A, 2003, 107, 7269-7277.

47 S. Maclot, D. G. Piekarski, R. Delaunay, A. Domaracka, A. Méry, V. Vizcaino, J.-Y. Chesnel, F. Martín, M. Alcamí,
B. A. Huber, L. Adoui, P. Rousseau and S. Díaz-Tendero, Eur. Phys. J. D, 2014, 68, 149.

48 R. Brédy, J. Bernard, L. Chen, G. Montagne, B. Li and S. Martin, J. Chem. Phys., 2009, 130, 114305.

49 M. E. Sanz, A. Lesarri, M. I. Peña, V. Vaquero, V. Cortijo, J. C. López and J. L. Alonso, J. Am. Chem. Soc., 2006, 128, 3812-3817.

50 M. J. Frisch, G. W. Trucks, H. B. Schlegel, G. E. Scuseria, M. A. Robb, J. R. Cheeseman, G. Scalmani, V. Barone, B. Mennucci, G. A. Petersson, H. Nakatsuji, M. Caricato, X. Li, H. P. Hratchian, A. F. Izmaylov, J. Bloino, G. Zheng, J. L. Sonnenberg, M. Hada, M. Ehara, K. Toyota, R. Fukuda, J. Hasegawa, M. Ishida, T. Nakajima, Y. Honda, O. Kitao, H. Nakai, T. Vreven, J. A. Montgomery, Jr., J. E. Peralta, F. Ogliaro, M. Bearpark, J. J. Heyd, E. Brothers, K. N. Kudin, V. N. Staroverov, R. Kobayashi, J. Normand, K. Raghavachari, A. Rendell, J. C. Burant, S. S. Iyengar, J. Tomasi, M. Cossi, N. Rega, J. M. Millam, M. Klene, J. E. Knox, J. B. Cross, V. Bakken, C. Adamo, J. Jaramillo, R. Gomperts, R. E. Stratmann, O. Yazyev, A. J. Austin, R. Cammi, C. Pomelli, J. W. Ochterski, R. L. Martin, K. Morokuma, V. G. Zakrzewski, G. A. Voth, P. Salvador, J. J. Dannenberg, S. Dapprich, A. D. Daniels, Ö. Farkas, J. B. Foresman, J. V. Ortiz, J. Cioslowski and D. J. Fox, Gaussian 09 Revision B.01, 2010.

51 T. Bergen, X. Biquard, A. Brenac, F. Chandezon, B. A. Huber, D. Jalabert, H. Lebius, M. Maurel, E. Monnand, J. Opitz, A. Pesnelle, B. Pras, C. Ristori and J. C. Rocco, Rev. Sci. Instrum., 1999, 70, 3244-3253.

52 F. Chandezon, B. Huber and C. Ristori, Rev. Sci. Instrum., 1994, 65, 3344-3353.

53 J. L. Holmes and T. S. Jean, J. Mass Spectrom., 1970, 3, 1505-1518.

54 A. G. Harrison, Mass Spectrom. Rev., 2009, 28, 640-654.

55 G. A. Olah, G. K. S. Prakash and Y. L. Chao, Helv. Chim. Acta, 1981, 64, 2528-2530.

56 A. I. Kuleff and L. S. Cederbaum, Chem. Phys., 2007, 338, 320-328.

57 J. Andrés, L. R. Domingo, M. T. Picher and V. S. Safont, Int. J. Quantum Chem., 1998, 66, 9-24.

58 J. Eland, F. Wort and R. Royds, J. Electron Spectrosc. Relat. Phenom., 1986, 41, 297-309.

59 V. E. Selezneva, A. I. Chmarin, T. L. Golitsyna and D. S. Zhuk, Russ. Chem. Bull., 1975, 24, 189.

60 K. E. Kruglyakova, D. L. Zybina, B. Ulanov and N. M. Emanuel, Dokl. Akad. Nauk SSSR, 1965, 718, 161.

61 G. Depke, N. Heinrich and H. Schwarz, Int. J. Mass Spectrom. Ion Processes, 1984, 62, 99-117.

62 S. Naumov, I. Janovský, W. Knolle, R. Mehnert and D. A. Turin, Radiat. Phys. Chem., 2005, 73, 206-212.

63 M. A. Freitas, R. A. J. O'Hair, J. A. R. Schmidta, S. E. Tichy, B. E. Plashko and T. D. Williams, J. Mass Spectrom., 1996, 31, 1086-1092.

64 M. C. Blanchette, J. L. Holmes, C. E. C. A. Hop, F. P. Lossing, R. Postma, P. J. A. Ruttink and J. K. Terlouw, J. Am. Chem. Soc., 1986, 108, 7589-7594. 
65 M. H. Lien and A. C. Hopkinson, J. Am. Chem. Soc., 1988, 110, 3788-3792.

66 D. Schröder, N. Goldberg, W. Zummack, H. Schwarz, J. C. Poutsma and R. R. Squires, Int. J. Mass Spectrom. Ion Processes, 1997, 165-166, 71-82.
67 A. Cruz-Torres, A. Galano and J. R. Alvarez-Idaboy, Phys. Chem. Chem. Phys., 2006, 8, 285-292.

68 S. Kwok, Astrophys. Space Sci., 2009, 319, 5-21.

69 T. Wang and J. H. Bowie, Org. Biomol. Chem., 2010, 8, 4757.

70 J. E. Bartmess, Mass Spectrom. Rev., 1989, 8, 297-343. 